\title{
Ultrasonography-guided coaxial trucut biopsy at breast masses: Our clinical experience
}

\section{Meme kitlelerinde ultrasonografi eşliğinde koaksiyel tru-cut biyopsi: Klinik tecrübemiz}

\author{
Cetin Imamoglu', Fatma Gül Imamoglu², Zehra Hılal Adıbelli ${ }^{3}$, Ahmet Bayrak ${ }^{1}$, Bilgin Kadri \\ Arıbaş $^{1}$, Hatice Filiz Erdil ${ }^{1}$ \\ ${ }^{1}$ Abdurrahman Yurtaslan Onkoloji Eğitim Ve Araştırma Hastanesi, Radyoloji Kliniği, Ankara \\ ${ }^{2}$ Atatürk Eğitim Ve Araştırma Hastanesi, Radyoloji Kliniği, Ankara \\ ${ }^{3}$ Bozyaka Eğitim Ve Araştırma Hastanesi, Radyoloji Kliniği, İzmir
}

\section{ÖZET}

GİRIŞ ve AMAÇ: Bu çalışmada girişimsel radyoloji ünitemizde US kılavuzluğunda yaptığımız koaksiyel meme TCB sonuçlarını ve tanısal değerini retrospektif olarak güncel literatür ışı̆̆ında gözden geçirdik.

YÖNTEM ve GEREÇLER: Çalışmamıza toplam 343 hasta dahil edildi. Lezyonlar breast imaging reporting and data system (BI-RADS) kullanılarak ultrasonografik olarak BI-RADS 3, BI-RADS 4 ve BI-RADS 5 olarak kategorize edildi. Tüm lezyonlardan $18 \mathrm{G}$ tam otomatik TCB iğnesi ile multipl biyopsiler alındı. İstatistiksel analiz, SPSS version 18.0 ile yapıldı.

BULGULAR: Histopatolojik inceleme sonrası lezyonların 129 tanesi malign, 214 tanesi ise benign olarak tespit edildi. Kitlelerin en sık yerleşim yeri 162 lezyon ile meme üst dış kadranıydı. Retroareolar yerleşimli lezyonların benignide yönünden istatistiksel olarak anlamlı olduğu görüldü. Radyolojik değerlendirmede lezyonların \% 39,1 BIRADS 3, \% 33,2 BIRADS 4 ve \% 27,7 BIRADS 5 olarak sinıflandırıldı. BIRADS 3 lezyonlarda benignide için ultrasonografinin pozitif prediktif değeri \% 100 olarak hesaplandı. BIRADS 4 lezyonlarda malignite için ultrasonografinin pozitif prediktif değeri \% 29,8 olarak hesaplandı. BIRADS 5 lezyonlarda malignite için ultrasonografinin pozitif prediktif değeri \%100 olarak değerlendirildi.

TARTIŞMA ve SONUÇ: Bizim çalışmamızda tanısal yetersiz TCB mevcut değildi. Ultrasonografik olarak 134 olgu BIRADS 3 tanısı almıştı ve hepsi benign olarak raporlandı. Bu bulgu BIRADS-3 lezyonları takip yönünden cesaretlendirmektedir. Çalışmamızda BIRADS 4 lezyonların \% 29,8'i malign tanı aldı. Bununla birlikte bu grup lezyonların büyük kısmını benign lezyonlar oluşturmaktadır. $\mathrm{Bu}$ durum gereksiz biyopsileri beraberinde getirmekle birlikte BIRADS 4 lezyonlarda TCB endikasyonuna neden olmaktadır. BIRADS 5 olarak yorumlanan 95 olgunun tümü de malign tanı almıştır. Bu nedenle BIRADS 5 lezyonlara mutlaka TCB yapılmalıdır. Sonuç olarak meme lezyonlarının US ile sınıflandırılması ve ultrasonografi kılavuzluğunda yapılan koaksiyel TCB, hızlı uygulanan, hızlı sonuç alınan, hastaya fazla rahatsızlık vermeden daha güvenilir preoperatif planlamaya olanak sağlayan etkin bir yöntemdir.

Anahtar Kelimeler: ultrasonografi, BI-RADS, koaksiyel trucut biyopsi,

\footnotetext{
ABSTRACT

INTRODUCTION: In this study, we retrospectively reviewed the results and diagnostic value of the US guided coaxial breast TCB with current literature.

METHODS: A total of 343 patients were included in the study. The lesions were categorized as BI-RADS 3, BI-RADS 4 and BI-RADS 5 by using breast imaging reporting and data system (BI-RADS). Multiple biopsies were obtained from all lesions with coaxial fully automated TCB needle. Statistical analysis was performed with SPSS version 18.0 .
} 
RESULTS: After histopathological examination, 129 lesions were malign and 214 lesions were benign. The most frequent site of the masses was the upper external quadrant of the breast with 162 lesions. Retroareolar lesions were found to be benign in terms of statistical significance. Radiologically, $39.1 \%$ of the lesions were classified as BIRADS 3, 33.2\% as BIRADS 4, and 27.7\% as BIRADS 5. For BIRADS 3 lesions, the positive predictive value of ultrasonography for benign is $100 \%$. The positive predictive value of ultrasonography for malignancy in BIRADS 4 lesions was calculated to be $29.8 \%$. For BIRADS 5 lesions, the positive predictive value of ultrasonography for malignancy was evaluated as $100 \%$.

DISCUSSION and CONCLUSION: In our study, there was no non-diagnostic TCB. All of the 134 patients classifying BI RADS 3 were reported as benign. This finding encourages follow-up of BIRADS-3 lesions. Approximately $29,8 \%$ of BIRADS 4 lesions were diagnosed as malign in our study. However, most of these group lesions are benign lesions. This situation leads to the indication of TCB in BIRADS 4 lesions, while bringing in unnecessary biopsies. All 95 patients who were interpreted as BIRADS 5 were diagnosed as malignant. Therefore, BIRADS 5 lesions should be performed with biopsy. As a conclusion; Classification of breast lesions by US and ultrasonography guided coaxial TCB is an effective method which enables faster reliable preoperative planning without causing discomfort to the patient.

Keywords: Ultrasonography, BI-RADS, coaxial trucut biopsy

\section{Gİiș}

Meme kanseri kadınlarda en sık görülen kanser türüdür(1,2). Son y1llarda başarılı tarama programları ile meme lezyonlarının erken evrede ve küçük boyutlu tespit edilme oranı artmıştır (3). Klinik ve radyolojik olarak memede kuşkulu bir lezyon saptandığında histopatolojik değerlendirmede yüksek doğruluk oranları nedeni ile ilk seçenek tru-cut biyopsi (TCB) olmalıdır(4). TCB ile açık biyopsiden farklı olarak, lenfatikler sağlam kaldığı için sentinal lenf nodülü haritalama ve meme koruyucu ameliyat yapma olasıllğ 1 $\operatorname{artar}(5)$. Ayrica TCB malignite tespit edildiğinde kanseri kategorize etmeye ve reseptör çalışmalarına da imkan vermektedir(6). Bu durum daha iyi bir preoperatif tedavi planlamasına olanak sağlar. $\mathrm{Biz}$ bu çalışmada girişimsel radyoloji ünitemizde US kılavuzluğunda yaptığımız TCB sonuçlarını ve tanısal değerini retrospektif olarak güncel literatür 1şığında gözden geçirdik.

\section{GEREÇ VE YÖNTEM}

\section{Çalışma Populasyonu;}

Çalışmamıza Ağustos 2013 ile Ocak 2016 tarihleri arasında, İzmir Bozyaka Eğitim ve Araştırma Hastanesi girişimsel radyoloji ünitesine US k1lavuzluğunda tru-cut meme biyopsisi için gönderilen toplam 343 hasta dahil edildi. TCB öncesi tüm hastalara işlem anlatıldı ve yazılı bilgilendirilmiş onamları alındı. Bu çalışma retrospektif olarak yapıldığı için etik kurul kararı alınmamıştır.

\section{Radyolojik Değerlendirme;}

Lezyonlar breast imaging reporting and data system (BI-RADS) kullanılarak ultrasonografik olarak BIRADS 3, BIRADS 4 ve BIRADS 5 olarak kategorize edildi. BIRADS 3 lezyonu olan hastalara ailede meme kanser öyküsü, takipte lezyonda boyut artışı, veya rahatsızlık oluşturduğu için hasta ve klinisyenin istemiyle biyopsi yapılmıştır. Lezyonun bulunduğu taraf sağ ve sol olarak, memedeki yerleşimi ise; üst dış kadran, üst iç kadran, alt iç kadran, alt dış kadran ve retroareolar bölge olarak grupland.

\section{Tru-cut Biyopsi İşlemi;}

İşlem öncesinde profilaktik antibiyoterapi uygulanmadı. Klinik öykü hariç hemogram ve koagulasyon testleri istenmedi. Hasta sedyeye uygun pozisyon verilerek yatırıldı. Tüm hastalara işlem öncesi lezyon olduğu bilinen meme ve aksillaya $7 \mathrm{Mhz}$ lineer prob (Sonoscape, Shenzhen, China) ile US yapıldı. İşlem için steril masa hazırlandı. US probu dezenfektan ile temizlendikten sonra tek kullanımlık steril kılıf giydirildi. Biyopsi bölgesi iyotlu antiseptik ile temizlendi. Hasta delikli steril örtüyle örtüldü. US eşliğinde $21 \mathrm{G}$ $(0,80 \times 38 \mathrm{~mm}, 5 \mathrm{ml})$ iğne ile yaklaş1k $2 \mathrm{ml}$ lokal anestezi yapıldı. Serbest el tekniği ile probun kısa kenarından $17 \mathrm{G}$ koaksiyel iğne ucu sürekli izlenerek lezyonun sınırına yerleştirildi. Sonrasında US eşliğinde koaksiyel iğnenin içinden $18 \mathrm{G}$ disposable tam otomatik TCB iğnesi ile lezyonun tüm kadranlarından boyutuna göre değişen 4-8 arasında multipl biyopsiler alındi. Ateşleme sırasında toraksa istenmeyen bir girişe engel olmak için iğnenin göğüs duvarına göre pozisyonuna özellikle 
dikkat edildi. Alınan spesimenler steriliteyi korumak için işlem boyunca steril bir eldiven üzerinde biriktirildi. Sonrasında bütünlüğüne zarar vermeden formol solüsyonu içinde ve kapalı bir kapta patoloji laboratuvarına gönderildi. İşlem bitince iğne giriş yeri steril spanç ile kapatıldı ve yaklaşı 10 dakika kompresyon uygulandi. Hasta başka bir odada k1sa bir süre gözlendikten sonra taburcu edildi. İşlem sırasında ve sonrasında işleme bağlı bir komplikasyon gözlenmedi.

\section{İstatistik Ínceleme;}

Hastalar 40 yaş üstü ve 40 yaş altı olarak iki gruba ayrildı. İstatistiksel analiz, SPSS version 18.0 (SPSS, Chicago, IL) ile yapild. Radyolojik sinıflama ve patolojik sonuçları karşılaştırmak için ki-kare $(\chi)$ testi kullanıldı. İstatistiksel olarak $\mathrm{p}<0,05$ anlamlı kabul edildi.

\section{BULGULAR}

Çalışmaya dahil edilen olguların ortalama yaşı 48,04 (15-98) idi. Lezyon büyüklüğü $5 \mathrm{~mm}$ ile $130 \mathrm{~mm}$ arasında değişmekte olup ortalama boyut $21,89 \mathrm{~mm}$ idi. Histopatolojik inceleme sonras1 lezyonların 129 tanesi malign, 214 tanesi ise benign olarak tespit edildi. Lezyonların 161 (60 malign, 101 benign) i sağda, 182 (69 malign, 113 benign) si soldaydi. Kitlelerin en sık yerleşim yeri 162 (64 malign, 98 benign) lezyon ile meme üst diş kadranıydı. Diğer lokalizasyonlar sirasıyla üst iç kadran 64 (25 malign, 39 benign), alt dış kadran 48 (19 malign, 29 benign), retroareolar bölge 38 ( 8 malign, 30 benign) ve alt iç kadran 31 (13 malign, 18 benign) olarak tespit edildi.

Retroareolar yerleşimli lezyonların benignide yönünden istatistiksel olarak anlamlı olduğu görüldü. Diğer lokalizasyonlarda malign ve benign lezyonların memede yerleşimleri arasında istatistiksel fark izlenmedi.

Radyolojik değerlendirmede lezyonlarin 134 tanesi (\% 39,1) BIRADS 3, 114 tanesi (\% 33,2) BIRADS 4 ve 95 tanesi (\% 27,7) BIRADS 5 olarak siniflandirıldı.

Histopatolojik inceleme sonrasinda benign lezyonların 119 tanesi fibroepitelyal lezyon, 32'si fibrokistik değişiklikler, 24'ü mastit, 25'i adenozis, 7'si yağ nekrozu, 4'ü intraduktal papillom ve 3'ünde diğer patolojiler mevcuttu (Tablo 1). Bu olgulardan
22 tanesine lezyon eksizyonu yapıld1. Bu hastalarm 18 tanesi patoloji sonucu sklerozan adenozis, filloides tümör, intraduktal papillom ve radial skar tanis1 olan hastalard. Lezyonların 4 tanesi ise kozmetik nedenler dolayısıyla eksize edildi. Hepsinde patoloji sonucu tru-cut biyopsi ile uyumluydu. Diğerlerine ek cerrahi işlem yapılmadı ve takibe alındı. Bu olguların takip süresi 3-30 ay arasında değişmekteydi (ortalama 18,1 ay).

Malign olguların ise 117 tanesi invasiv duktal karsinoma, 6 tanesi lobuler karsinoma, 2 tanesi müsinöz karsinoma ve 4 tanesi diğer maligniteler olarak tesbit edildi (tablo 1). Bunlara uygun cerrahi ve gerekli ek tedaviler uyguland.

Tablo 1. Lezyonların histopatolojik dağılımları

\begin{tabular}{|c|c|c|c|}
\hline Histopatolojik Grup & $\begin{array}{l}\text { Lezyon } \\
\text { Saylsı }\end{array}$ & Histopatolojik Tanı ve Sayısı & \\
\hline Benign & 196 & $\begin{array}{l}\text { Fibroepitelyal lezyon/ } \\
\text { Filloides tümör } \\
\text { Fibrokistik değişiklik } \\
\text { Mastit/Granülomatöz mastit } \\
\text { Adenozis/ Sklerozan adenozis } \\
\text { Yağ nekrozu } \\
\text { İntraduktal papillom } \\
\text { Psödoanjiomatöz stromal } \\
\text { hiperplazi } \\
\text { Apokrin metaplazi } \\
\text { Radial skar }\end{array}$ & $\begin{array}{l}113 / 6 \\
32 \\
14 / 10 \\
18 / 7 \\
7 \\
4 \\
1 \\
1 \\
1\end{array}$ \\
\hline Malign & 129 & $\begin{array}{l}\text { İnvaziv duktal karsinoma } \\
\text { Lobuler karsinoma } \\
\text { Müsinöz karsinoma } \\
\text { Nöroendokrin karsinoma } \\
\text { İnvaziv kribriform karsinoma } \\
\text { Papiller karsinoma } \\
\text { Paget hastalı̆ı }\end{array}$ & $\begin{array}{l}117 \\
6 \\
2 \\
1 \\
1 \\
1 \\
1\end{array}$ \\
\hline Toplam & 343 & & \\
\hline
\end{tabular}

Radyolojik değerlendirme ile histopatolojik sonuçlar arasında yüksek derecede uyum mevcuttu.

Radyolojik olarak 134 olguya BIRADS 3 tanısı konmuştu ve bunların hepsinin histopatolojisi benign olarak raporland. BIRADS 3 lezyonların hiçbiri malign olarak raporlanmadi (Tablo 2). BIRADS 3 lezyonlarda benignide için ultrasonografinin pozitif prediktif değeri \% 100 olarak hesaplandi. 
Tablo 2- Yaş, ultrasonografik BIRADS kategorileri ve histopatolojik sonuçların karşılaştırılması

\begin{tabular}{|c|c|c|c|c|c|c|}
\hline \multirow[t]{2}{*}{ Histopatolojik Sonuç } & \multicolumn{2}{|c|}{ BIRADS 3} & \multicolumn{2}{|c|}{ BIRADS 4} & \multicolumn{2}{|c|}{ BIRADS 5} \\
\hline & $y a s ̧<40$ & $y a s ̧>40$ & $y a s ̧<40$ & $y a s ̧>40$ & $y a s ̧<40$ & $y a s ̧>40$ \\
\hline Benign & 59 & 75 & 9 & 71 & - & - \\
\hline Malign & - & - & 1 & 33 & 14 & 81 \\
\hline Toplam & & & 1 & & & \\
\hline
\end{tabular}

BIRADS 4 olarak sinıflandırılan 114 olgunun 80 'i benign tan 1 alırken 34 tanesi malign tan ald1 (Tablo 2). BIRADS 4 lezyonlarda malignite için ultrasonografinin pozitif prediktif değeri \% 29,8 olarak hesaplandi.

Radyolojik olarak BIRADS 5 yorumlanan 95 olgunun tümü de malign tanı aldı (Tablo 2). BIRADS 5 lezyonlarda malignite için ultrasonografinin pozitif prediktif değeri $\% 100$ olarak değerlendirildi.

40 yaş üstü grupta 260 lezyon, 40 yaş altı grupta 83 lezyon izlendi. Ayrıca yaş grupları ile radyolojik BIRADS arasinda anlamlı bir ilişki mevcuttu (Tablo 2). BIRADS 3 lezyonlar 40 yaş altı grupta orantısal olarak s1k iken BIRADS 5 lezyonlar 40 yaş üstü grupta sıktı. Benzer ilişki yaş grubu ile histopatolojik malign tanı arasinda da mevcuttu. 40 yaş altı gruptaki 83 lezyonun 15 tanesi malign, 40 yaş üstü grupta 260 lezyonun 114 tanesi malign olarak (sirasiyla \% 18,1 ve \%43,8) raporlandı. Çalışmamızda malignite izlenen en küçük hastanın yaşı 28 olarak tespit edildi.

\section{TARTIŞMA ve SONUÇ}

TCB meme lezyonlarını araştırmada günümüzde en yaygın kullanılan yöntemdir $(4,6)$. Tanısal olmayan TCB oranları tecrübeli ellerde $\% 1$ civarında veya daha azdır (7). Bizim çalışmamızda tanısal yetersiz olgu mevcut değildi. Bazı çalışmalarda TCB ile yapılan biyopsilerde alınan tek örnek ile tanısal yeterlilik \%70 düzeylerinde iken, örnekleme sayısı dörde çıkarıldığında \%100'e ulaşmaktadır (8). Biz de lezyonun tüm kadranlarını tarayan multipl biyopsiler alınmasını tanısal yeterliliği artıran gerekli bir faktör olarak görüyoruz. Koaksiyel iğne kullanımının hastaya fazla rahatsızlık vermeden ve işlem süresini uzatmadan multipl biyopsi almak için önemli bir yöntem olduğunu da belirtmek gerek. Ayrıca TCB nin ultrason eşliğinde ve yeterli deneyime sahip girişimsel radyolog tarafından yapılmasının önemli olduğunu düşünmekteyiz.

Patoloji sonucu benign gelen olgulardan 22 hastaya histopatolojik tanıs1, lezyonun boyutu ve hastaya verdiği rahatsızlık nedeniyle lezyon eksizyonu yapild. $\mathrm{Bu}$ hastalara cerrahi öncesi biyopsi yapılmış olmas1 ve lezyonun benign olduğunun bilinmesi meme dokusunu korumada ve uygun kozmetik sonuca ulaşmada oldukça yararlı oldu. Diğer hastalara ek cerrahi işlem yapılmadı ve bu olguların hepsi takibe alındı. Takipte lezyonlarda malignite gelişmedi. İki olguda takipte lezyon boyutunda büyüme saptanması nedeni ile yeniden biyopsi yapıldı. Bunların histopatoloji sonucu da aynı benign tanı olarak raporlandi. Patoloji sonucu malign olan hastalara cerrahi yapıldı ve histopatolojik tanının biyopsi ile aynı olduğu görüldü. Literatürde TCB'nin tanı koymadaki sensitivitesi \%88-98 arasında bildirilmektedir (9). Bizim çalışmamızda TCB nin tanı koymadaki sensitivitesi \%100 olarak bulundu. BIRADS siniflamas1 radyologlar arasinda görüş birliği sağlamayı ve raporun daha anlaşılır olmasını amaçlamaktadır(10). Çalışmamızda ultrasonografik BIRADS kategorileri ile histopatolojik sonuçlar arasında literatüre benzer bir uyum izlendi.

Ultrasonografik olarak 134 olgu BIRADS 3 tanısı almıştı ve hepsi benign olarak raporland1. Malign olarak raporlanan lezyon olmadi. BIRADS 3 lezyonlarda çalışmamızda hiç malign lezyon izlenmemesi hasta populasyonunun biyopsi için gönderilmiş belirli bir gruptan oluşmasına bağlı olabilir. BİRADS 3 lezyonlarda 6 aylik izlemde boyutsal ya da biçimsel değişiklik olursa, yüksek risk taşıyan olgularda, takibe gelemeyecek ya da HRT alacak olgularda ve ileri yaşta ortaya çıkması durumunda biyopsi 
önerilmektedir (11). Bununla birlikte bu çalışmadan elde ettiğimiz bulgular bizi tüm BIRADS-3 hastaları takip yönünden cesaretlendirmektedir.

BIRADS 4 lezyonlarm 34 tanesi malign, 80 tanesi benign tanı aldı. Çalışmamızda BIRADS 4 lezyonların yaklaşık $\% 30$ 'u malign tanı almakla birlikte bu grup lezyonların da büyük kısmını benign lezyonlar oluşturmaktadır. $\mathrm{Bu}$ nedenle BIRADS 4 lezyonlarda ultrasonografik bulguların diğer radyolojik modalitelerle birlikte değerlendirilmesinin yararlı olacağını düşünmekteyiz. Günümüzde hastanın yaşı uygunsa mammografi bir tarama testi olarak kullanılmaktadır. Ayrıca meme MR yüksek yumuşak doku çözünürlüğü, dinamik inceleme imkanı ve diffüzyon gibi bazı özel sekanslarının olması nedeniyle bu tip lezyonları değerlendirmede önemli bir yere sahiptir (12). Meme elastografi de malign lezyonları benign lezyonlardan ayırmada yaralı olduğu bildirilmektedir (13). Ancak günümüzde hiçbir yöntem meme lezyonlarını tam olarak benign ve malign olarak ayıramamaktadır. $\mathrm{Bu}$ durum gereksiz biyopsileri beraberinde getirmekle birlikte BIRADS 4 lezyonlarda TCB endikasyonuna neden olmaktadır $(10,14)$.

BIRADS 5 olarak yorumlanan 95 olgunun tümü de malign tanı almıştır. Bu durum sadece kesin sonografik bulgular içeren hastaların BIRADS 5 olarak kabul edilmesine diğerlerinin BIRADS 4 olarak sınıflanmasına bağlı olabilir. Ancak BIRADS 5 lezyonlardaki yüksek malignite oranı nedeniyle BIRADS 5 lezyonlara mutlaka TCB yapılmalıdır.

Çalışmadaki bir diğer bulguda benign lezyonların 40 yaş altı grupta ve malign lezyonlarında 40 yaş üzeri grupta orantısal olarak sik izlenmesiydi. Bu populasyonda meme kanseri görülme sıklığı ile uyumludur (1). Meme kanseri genellikle yaşla sıklığı artan kanserlerdendir (1,2). Bununla birlikte çalışmamızda malignite tespit edilen en küçük hastanın yaşı 28 olup meme kanserinin oldukça

\section{REFERANSLAR}

1. T.C. Sağlık Bakanlı̆̆ı Türkiye Halk Sağlı̆̆ Kurumu, Türkiye Kanser İstatistikleri, Ankara 2017 genç yaşlarda da görülebileceği unutulmamalidir.

TCB'ye bağlı enfeksiyon, hematom, akciğer yaralanması gibi komplikasyonlar olabilir. $\mathrm{Bu}$ çalışmaya alınan olguların hiçbirinde bu komplikasyonlar izlenmedi. $17 \mathrm{G}$ koaksiyel iğne ve $18 \mathrm{G}$ tam otomatik TCB iğnesi kullanmanın bu durumda etkili olduğunu düşünmekteyiz. Yeterli sayıda ve uygun alandan örnekleme yapıldığında meme biyopsisi için $18 \mathrm{G}$ iğnenin yeterli olduğunu gördük. Daha kalın iğnelerin, küçük lezyonların örneklenmesinde ve yoğun fibrokistik parankime sahip memelerde penetrasyon güçlügüne ve dolayısıyla komplikasyona neden olma riski nedeniyle, biz meme biyopsilerinde $18 \mathrm{G}$ tam otomatik iğneleri önermekteyiz. Koaksiyel iğne kullanımı lezyona ulaşmak için tek giriş yolu avantajı sağlamakta, işlem süresini kısaltmakta ve komplikasyonları azaltmaktadır. Girişim öncesi profilaksi yapılmasına cerrahi hijyenik önlemlere uyulduğunda gerek olmadığını düşünmekteyiz. İşlem sırasında lezyon çevresinin US ile değerlendirilerek büyük damarlardan kaçınılması ve işlem sonrasında (10 dakika) kompresyonun hematomun gelişiminin önlenmesinde etkili olmaktadır. Ek maliyet getirebilecek hemogram ve koagulasyon tetkiklerine gerek olmadığını düşünmekteyiz.

Çalışmamızın retrospektif olması, mammografi, meme MR, meme elastografi gibi görüntüleme yöntemlerini içermemesi, BIRADS- 3 hastalarda hiç malign histopatolojik tanı, BIRADS 5 hastalarda hiç benign histopatolojik tan1 olmamas1 ve cerrahi yapılmayan hastaların ortalama takip süresinin kısa olması (18,1 ay) başlıca kısıtlamalarıdır.

Sonuç olarak meme lezyonlarının US ile siniflandirılmasi ve ultrasonografi kılavuzluğunda yapılan TCB, hızlı uygulanan, hızlı sonuç alınan, hastaya fazla rahatsızlık vermeden daha güvenilir preoperatif planlamaya olanak sağlayan etkin bir yöntemdir.
2. Cameron JL. Current surgical therapy. 9nd edition. Mosby Ine, Philadelphia, PA, USA, 2008.

3. Menezes GL, Knuttel FM, Stehouwer BL, Pijnappel RM, van den Bosch MA. Magnetic resonance imaging in breast cancer: A literature review and 
future perspectives. World J Clin Oncol 2014;5(2):61-70.

4. van Breest Smallenburg, Vivian, et al. "Trends in breast biopsies for abnormalities detected at screening mammography: a population-based study in the Netherlands." British journal of cancer 109.1 (2013): 242-248.

5. Ernst MF, Roukema JA: Diagnosis of non-palpable breast cancer: a review. The Breast, 2002; 11: 13-22

6. Verkooijen HM, Peeters PH, Buskens E, Koot VC, Borel Rinkes I, Mali WP, van Vroonhoven TJ.Diagnostic accuracy of large-core needle biopsy for nonpalpable breast disease: a meta-analysis. $\mathrm{Br} \mathrm{J}$ Cancer 2000;82(5):1017-21.

7. Radhakrishna S, Gayathri A, Chegu D. Needle core biopsy for breast lesions: An audit of 467 needle core biopsies. Indian J Med Paediatr Oncol 2013;34(4):25256.

8. Wu YC, Chen DR, Kuo SJ (2006) Personal experience of ultrasound-guided 14-gauge core biopsy of breast tumor. Eur J Surg Oncol 2006; 32: 715-8.,
9. Brunner AH, Sagmeister $\mathrm{T}$, Kremer J, Riss $\mathrm{P}$, Brustmann $H$. The accuracy of frozen section analysis in ultrasoundguided core needle biopsy of breast lesions. BMC Cancer 2009; 24(9):341.

10. ACR BI-RADS Atlas, Ultrasound 2013

11. Meme Kanserinde Tan1, 15-19 Kasım 2006, I. Ulusal Meme Kanseri Konsensus Toplantıs1, "Meme Kanserinde Tanı Basamakları ve Standartlar" Panelinde Yapılan Tartışmaların ve Konsensus Kurulu Oylamalarının Raporudur.

12. Sardanelli F, Giuseppetti GM, Canavese G, Cataliotti L, Corcione S, Cossu E, et al. Indications for breast magnetic resonance imaging. Consensus document "Attualita in senologia", Florence 2007. Radiol Med 2008; 113: 1085-95.

13. Ko KH, Jung HK, Kim SJ, Kim H, Yoon JH. Potential role of shear-wave ultrasound elastography for the differential diagnosis of breast non-mass lesions: preliminary report. Eur Radiol 2014; 24 : 305-11.

14. Sayek, İskender, ed. Temel Cerrahi. Güneş kitabevi, 2004. 